\title{
Isoniazid Induced Unilateral Gynecomastia: A Rare Case Report
}

\author{
Parul Bhardwaj ${ }^{1}$, Anju Bala ${ }^{2}$, Shivbrat $^{3}$, Vipan Garg ${ }^{4}$ \\ ${ }^{1}$ MD Internal Medicine, Civil Hospital Dehra (H.P.) \\ ${ }^{2}$ MD Pediatrics, Civil Hospital Nadaun (H.P.) \\ ${ }^{3}$ Junior Resident ENT, DRPGMC Kangra at Tanda (H.P.) \\ ${ }^{4}$ Senior Resident Anesthesia, DRPGMC Kangra at Tanda (H.P.)
}

Corresponding Author: Anju Bala

\begin{abstract}
Gynecomastia refers to glandular enlargement of male breast. It can be physiological, pathological, pharmacological and idiopathic. The present case report describes a case of isoniazid induced gynecomastia.
\end{abstract}

Keywords: Gynecomastia, antitubercular treatment (ATT), isoniazid.

\section{INTRODUCTION}

Gynecomastia is a glandular enlargement of the breast in males. The incidence of drug induced gynecomastia varies from $20-25 \%$, occasionally the anti tubercular therapy (ATT) is incriminated in the causation of gynecomastia ${ }^{1}$. Among them, only Isoniazid, and rarely Thoiacetazone, is reported to be associated with gynecomastia 2,3. Isoniazid has selective bactericidal activity for microbacteria ${ }^{4}$. Other like gastric intolerance, hepatitis, polyneuritis and allergic reactions are most common undesirable side effects of isoniazid. Here, we describe a case of isoniazid induced gynecomastia during the treatment of pulmonary tuberculosis.

\section{CASE REPORT}

52 year male presented to medicine OPD with chief complaints of fever, cough with white colour sputum and decrease appetite for last two weeks. There was also a history of two episodes of blood stained sputum. Then patient was advised for sputum for AFB stain and chest X-ray PA view. On investigations, patient had $3+$ AFB on smear, Rifampicin sensitive on CBNAAT and right upper lobe consolidation on chest $\mathrm{x}$-ray. On basis of these investigations, patient started on anti tubercular therapy under daily fixed dose combination schedule which include 4 tablets HRZE 75/150/400/275 mg per tablet (4 FDC). After starting ATT patient symptomatically improved, but after 3 months of having ATT patient developed painful enlargement of left breast. On local examination, there was a breast lump of size $3 \times 4 \mathrm{~cm}$ in diameter, mobile, tender, firm in consistency and not fixed to underlying tissue. On examination his secondary sexual characters and external genitalia were normal. There was no change in libido and sexual function. On investigations compete blood count, fasting blood sugar, liver function test, renal function test and thyroid function test were in normal limit. On the basis of all this, presumptive diagnosis of isoniazid induced gynecomastia was made and isoniazid was withheld and rest of the ATT as individual drugs continued. After stopping isoniazid, his breast swelling and tenderness resolved slowly over 2 months and is now on follow up. 


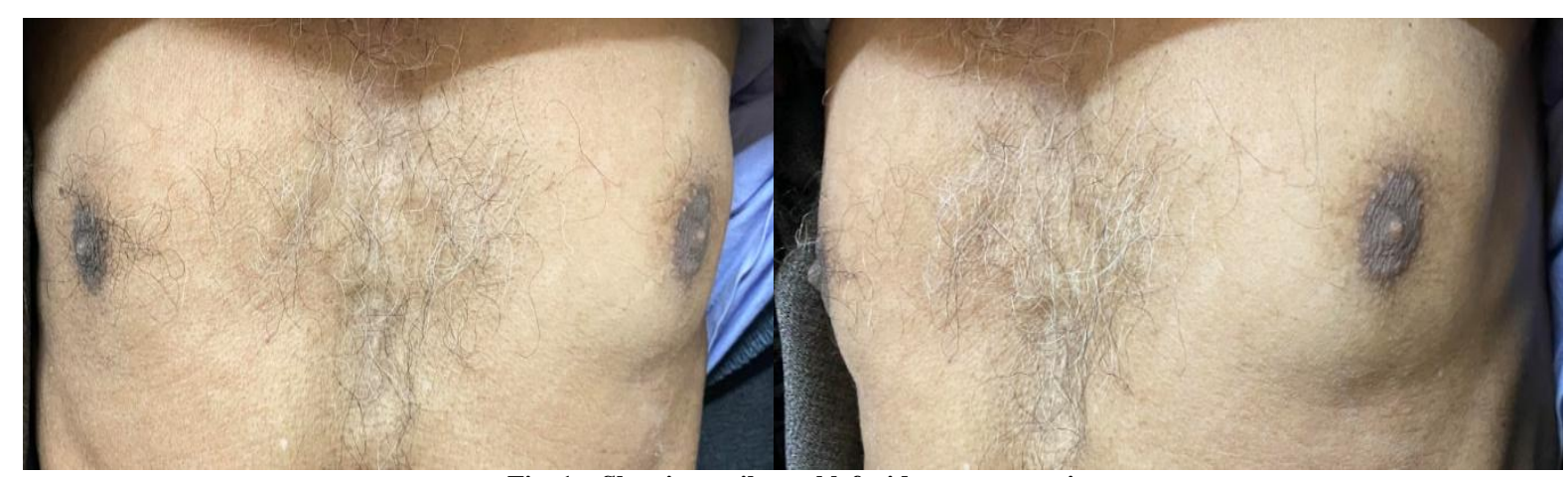

Fig. 1 - Showing unilateral left side gynecomastia.

\section{DISCUSSION}

Gynecomastia is defined as presence of palpable breast tissue in males. It is common particularly in the newborn period, at puberty and in the elderly. Gynecomastia results from an imbalance of androgenic and estrogenic influence on breast tissue. Estrogen stimulates the proliferation of breast tissue whereas androgen inhibits it. Gynecomastia occur when there is an increase in circulating or tissue level of estrogen, decrease in circulating or tissue level of androgen, altered serum androgen / estrogen ratio, increased breast sensitivity to estrogen (due to increase number of estrogen receptor) or decreased breast sensitivity to androgen (due to androgen receptor defect or drugs) ${ }^{5}$.

Gynecomastia may be due to various reasons which can be due to persistent pubertal gynecomastia; drug induced and can be idiopathic ${ }^{1}$. True gynecomastia is defined as glandular enlargement of breast tissue of more than $4 \mathrm{~cm}$ in men. It should always be differentiated from the pseudogynecomastia by demonstrating firm, fibrous cord like tissue that is concentric with nipple-areola complex in true gynecomastia by approximating thumb and forefinger together from either side of the breast during clinical examination 1. Common causes of gynaecomastia include obesity, ageing, primary or secondary hypogonadism, liver or renal failure, hyperthyroidism and less commonly feminizing adrenal and testicular tumour (e.g. Leydig or Sertoli cell tumour), gonadal or extra-gonadal HCG producing tumours and genetic conditions resulting in aromatase excess or androgen insensitivity 5

Drug can cause gynecomastia by its estrogenic activity (e.g. digoxin), by decreasing serum testosterone (e.g. ketoconazole, metronidazole by damaging or inhibiting Leydig cells), blocking androgen receptor (e.g. spironolactone, cimetidine,), increasing serum prolactin (e.g. spironolactone, antipsychotic) or via unknown mechanisms (e.g. proton pump inhibitors, highly active antiretroviral therapy) ${ }^{5}$.

Isoniazid is known to induce pyridoxine (vitamin B6) deficiency by inhibiting pyridoxal phosphokinase and by combining with pyridoxine to form isonicotinyhydrazide which is secreted in urine ${ }^{6}$. Isoniazid was also known to cause altered oestrogen- androgen metabolism. The physiologically active form of vitamin B-6, pyridoxal 5- phosphate (PLP), acts as a modulator of steroid hormone receptor mediated gene expression. Elevation of intracellular PLP leads to decreased transcriptional response to glucocorticoid hormones, progesterone, androgens and estrogen, while vitamin B-6 deficient cells exhibit enhanced responsiveness to steroid hormone ${ }^{7}$.

It has been postulated that isoniazid probably acts by a phenomenon called "Refeeding Gynecomastia", which is supposed to be caused by restoration of weight, gonadotrophin secretion, and gonadal function ${ }^{8}$. 


\section{CONCLUSION}

Most patients with gynecomastia generally require no treatment other than the removal of its cause. In case of drug induced gynecomastia, discontinuing the drug is the best cure. Specific treatment of gynecomastia is needed when it is causing embarrassment, pain or emotional discomfort and thus interfering patient's life. In such cases, surgery can be considered. In some cases where surgery is not possible, anti- oestrogens or aromatase inhibitors can be used ${ }^{9}$.

\section{Declaration of patient consent:}

The authors certify that they have obtained all appropriate patient consent forms regarding images and other clinical information to be reported in the journal.

\section{Acknowledgement: None}

\section{Conflict of Interest: None}

\section{Source of Funding: None}

\section{REFERENCES}

1. Braunstein GD. Gynecomastia. N Engl J Med 1993;328:490-5.

2. Khanna P, Panjabi C, Maurya V, Shah A. Isoniazid associated, painful, bilateral gynaecomastia. Indian J Chest Dis Allied Sci 2003;45:277-9.

3. Dixit R, Sharma $S$ Nawal CL. Gynaecomastia during antituberculosis chemotherapy with isoniazid. J Assoc Physicians India 2008;56:390-1.

4. Timmins GS, Deretic V. Mechanisms of action of isoniazid. Mol Microbiol. 2006; 62(5): 1220-7.

5. Narula HS, Carlson HE. Gynaecomastiapathophysiology, diagnosis and treatment. Nat Rev Endocrinol.2014;10(11):684-98.

6. Mandel W. Pyridoxine and the isoniazid induced neuropathy. Dis Chest.1959;36: 293-6.

7. Oka T. Modulation of gene expression by vitamin B6. Nutr Res Rev.2001;14(2):25766.

8. Bembo SA, Carlson HE. Gynaecomastia:its features, and when and how to treat it. Cleveland Clinic Journal of Medicine 2004;7:6.

9. Harrison's Principles of Internal medicine. XVIIth edition;Vol.II, New York;McGrawHill Co:2008;2318-9.

How to cite this article: Bhardwaj P, Bala A, Shivbrat et.al. Isoniazid induced unilateral gynecomastia: a rare case report. International Journal of Science \& Healthcare Research. 2021; 6(2): 50-52. DOI: https://doi.org/ 10.52403/ijshr.20210410 